\title{
Studi Literatur Riview: Gambaran Kesesuaian Dan Ketepatan Kode Diagnosa Pasien Rawat Inap Berdasarkan ICD-10
}

\section{Study Literature Review: Overview of Appropriateness and Accuracy of Diagnosis Codes of Inpatient Based on ICD-10}

\author{
Rahmadhani $^{1}$ \\ Deni Maisa Putra ${ }^{2}$ \\ Hiddati Aulia ${ }^{3}$ \\ Oktamianiza $^{4}$ \\ Yulfa Yulia ${ }^{5}$

\section{1,2,3,4,5) D3 Rekam Medis dan Informasi Kesehatan STIKES Dharma Landbouw Padang e-mail: rahmadhani17387@gmail.com}

\begin{abstract}
Quality medical records can be seen from the accuracy and compatibility of diagnoses in health services, given the importance of accuracy and compatibility of diagnostic codes. The research objective was to identify, identify, assess, and interpret the suitability and accuracy of the diagnostic code for inpatients with ICD-10 based on a literature review review. The method used is a literature review study with a descriptive analysis method carried out by analyzing literature review techniques including looking for similarities (compare), inequality (contrast), views (critize), compare (synthesize), and summarize with the literature sources used are 6 journals. The results of the review literature that the author tuned were still found that there were inconsistencies and inaccuracies in the coding of patient diagnoses in health facilities due to barriers to implementing SOPs and communication between coders and medical personnel which had an impact on the accuracy and suitability of diagnostic codes based on ICD-10. It is hoped that in further research, researchers can understand the stages of literature review and data analysis methods in related research regarding the accuracy and suitability of inpatient diagnosis codes and medical record handling in terms of input, process, and output to see more clearly the causes of incompleteness, and non-conformity of codification.
\end{abstract}

Keywords: accuracy, conformity, completeness, encoding.

\begin{abstract}
Abstrak
Rekam medis berkualitas dapat dilihat dari ketepatan dan kesesauian diagnosa di pelayanan kesehatan mengingat sangat pentingnya ketepatan dan kesesauian kode diagnosa. Tujuan penelitian untuk mengetahui, mengidentifikasi, menilai, dan menginterpetasikan terkait dengan gambaran kesesuaian dan ketepatan kode diagnosa pasien rawat inap dengan ICD-10 berdasarkan tinjauan literature review. Metode yang digunakan yaitu studi literature riview dengan Metode analisis deskriptif dilakukan dengan analisis teknik review literatur diantaranya mencari kesamaan (compare), ketidaksamaan (contrast), pandangan (critize), bandingkan (synthesize), dan ringkasan (summarize) dengan sumber pustaka yang digunakan adalah 6 jurnal. Hasil dari literatur review yang penulis talaah yaitu masih di temukan ada ketidaksesuaian dan ketidaktepatan pengkodean diagnosa pasien di fasilitas kesehatan di karenakan hambatan pelaksanna SOP dan komuniksi antar pengcode/coder dan tenaga medis
\end{abstract}


yang sehingga berdampak pada ketepatan dan kesesuaian kode diagnosa berdasarkan ICD-10. Diharapkan pada penelitian selanjutnya agar peneliti bisa memahami terhadap tahapan literature review dan metode ananlisis data dalam penelitian terkait tentang ketepatan dan kesesauian kode diagnosa pasien rawat inap serta penyenggaraan rekam medis di tinjau dari sisi input, proses, dan output untuk melihat lebih jelas penyebab terjarjadinya ketidak lengkapan dan ketidak sesauian kodefikasi.

Kata Kunci: ketepatan; kesesuaian; kelengkapan; pengkodean.

\section{Pendahuluan}

\begin{tabular}{lcr}
\multicolumn{1}{c}{ Rumah } & sakit adalah & institusi \\
pelayanan & kesehatan & yang \\
menyelenggaran pelayanan & kesehatan \\
perorangan secara paripurna yang
\end{tabular}
menyediakan pelayanan rawat inap, rawat jalan, dan gawat darurat. Rumah sakit harus memiliki sumber daya professional. Sumber daya rekam medis yang merupakan salah satu bagian dari rumah sakit (Undang-undang No 44 tahun 2009). Menurut Ismainar (2015) Rekam Medis merupakan berkas yang berisi catatan dan dokumen tentang identitas, anamnesa, diagnosa, pengobatan, tindakan, dan pelayanan penunjang yang diberikan kepada pasien selama mendapat pelayanan di unit rawat inap, rawat jalan, dangawat darurat serta catatan yang juga harus dijaga kerahasiaannya dan merupakan sumber informasi pasien qyang datang berobat ke rumah sakit. Salah satu data yang penting pendokumentasian rekam medis adalah kode diagnosis pasien, kode diagnosa pasien digunakansebagai acuan dalam penentuan besar biaya pelayanan kesehatan.

Menurut Hatta (2012) pengkodean adalah prosedur pemberian kode dengan menggunakan huruf dan angka. Kegiatan pengkodean meliputi pengkodean diagnosa dan pengkodean tindakan medis. Hal penting yang harus diperhatikan oleh tenaga perekam medis adalah ketepatan dalam pemberian kode diagnosa. Pengkodean diagnosa yang tepat akan menghasilkan data yang akurat dan berkualitas. Ketepatan dalam pemberian dan penulisan kode berguna untuk memberikan asuhan keperawatan, penagihan biaya klaim, meningkatakan mutu pelayanan, membandingkan data morbiditas dan mortalitas, menyajikan 10 besar penyakit, serta hal-hal lain yang berkaitan dengan pelayanan kesehatan.

Pengkodean diagnosis yang tepat akan menghasilkan data yang akurat dan berkualitas. Ketepatan dalam pemberian dan penulisan kode berguna untuk memberikan asuhan keperawatan, penagihan biaya klaim, meningkatakan mutu pelayanan, membandingkan data morbiditas dan mortalitas, menyajikan 10 besar penyakit, serta hal-hal lain yang berkaitandengan pelayanan kesehatan (Hatta, 2012).

Penentu ketepatan kode diagnosis utama penyakit juga dipengaruhi oleh spesifikasi penulisan diagnosis utama, masing-masing pernyataan diagnosis harus bersifat informatif atau mudah dipahami agar dapat menggolongkan kondisi-kondisi yang ada kedalam kategori ICD-10 yang paling spesifik. 
Kualitas hasil pengodean bergantung pada kelengkapan diagnosis, keterbacaan tulisan dokter, serta profesionalisme dokter dan petugas coding (WHO, 2010).

Berdasarkan penelitian di lakukan oleh Oktamianiza (2016) yang berjudul ketepatan pengodean diagnose utama penyakit pada rekam medis pasien rawat inap JKN (Jaminan Kesehatan Nasional) di RSI Siti Rahmah Padang, masih di temukan kode yang tidak tepat dikarenakan petugas coding tidak mencakup diagnosa yang ditulis atau kurang lengkap dalam pengodeannya, kurang lengkap dan kurang jelas dalam penulisan diagnosa di karenakan adanya peminjaman fomulir resume medis, masih adanya tulisan dokter yang sulit di baca sehingga menyulitkan petugas dalam mengkoding diagnose serta masih adanya diagnosa yang tidak di tulis oleh dokter di resume medis sehingga petugas harus melihat di fomulir ringkasan keluar pasien. Hal ini sejalan dengan penelitian yang di lakukan oleh Aurelia Anugerah Harvey Pepo dan Noor Yulia (2014) penelitian ini berjudul Kelengkapan penulisan diagnose pada resume medis terhadap ketepatan pengkodean klinis kasusu kebidanan berpendapat ketidak lengkapan penulisan dignosa pada resume di pengaruhi oleh petugas kurang berkomunikasi sehingga menyebabkan tidak di tulisnya diagnosa oleh dokter dan masih singkatan yang tidak sesaui dengan SOP yang ada. Mengingat pentingnya spesifikasi penulisan diagnosa utama terhadap ketepatan kode diagnosa utama yang dihasilkan, dan sebagai salah satu tolak ukur untuk kontrol kualitas di bagian pengodean (coding) unit rekam medis.
Berdasarkan uraian diatas, peneliti melakukan literatur review tentang “Gambaran Kesesuaian Dan Ketepatan Kode Diagnosa Pasien Rawat Inap Berdasarkan ICD-10".

\section{Metode Dan Material}

Jenis penelitian ini adalah penelitian literature riview. Pengumpulan data dilakukan dengan menggunakan data sekunder yang merupakan pendukung yang bersumber dari berbagai literatur maupun referensi-referensi yang ada menggunakan google scoler. Analisa data dilakukan dengan meggunakan teknik literatur review diantaranya mencari kesamaan (compare), cari ketidaksamaan (contrast), beri pandangan (critite), bandingkan (synthesize), dan ringkasan (summarize).

\section{Pembahasan}

Dalam melakukan telaah jurnal, dapat dilakukan dengan menggunakan teknik review literature antara lain menentukan kesamaannya (compare), menentukan ketidaksamaannya (contrast), beerikan pandangan (critize), bandingkan (synthesize), dan ringkasan (summarize).

\section{a. Kesamaan( Compare)}

Dari beberapa jurnal bias kita lihat bahwa terdapat kesamaan terhadap ketidak lengkapan dan ketidak kesesauian diagnosa dikarena ketidak jelasan penulisan diagnosa oleh dokter seperti singkatan dan tulisan berpengaruh terhadap keakuratan pengkodean sehingga koder sulit membaca dan memahami tulisan berdampak terhadap pengkodean yang salah. 
Hal ini juga didukung oleh penelitian Yeni Tri Utami, Nita Rosmalia (2017) dan Dewi Mardiawati,Tiara Febri Akika(2019) bahwa dokumen tidak dikode dikarenakan dokter tidak konsiten dalam penulisan diagnosa utama tepatnya di fomulir resume medis sehingga koder harus melihat fomulir rawat inap dengan teliti.

\section{b. Ketidaksamaan (Contrast)}

Dari beberapa jurnal juga ditemukan ketidak samaan antara satu sama lain. Dikarenakan ketidak lengkapan dan ketidak kesesauian pengisian kode diagnosa penyakit di sebabkan oleh kurangnya pengalaman dan motivasi koder. Hal ini bertentangan dengan penelitian yang dilakukan oleh Auelius Anugerah Pepo, Noor Yulia (2014) dan Dewi Mardiawati, Tiara Febri Akika (2019) ketidak lengkapan penulisan diagnosa penyakit pasien di resume medis di karenakan kurangnya komunikasi antar petugas koder dengan petugas medis sehingga tidak terjadinya kesalahan dan terdapat resume medis yang kosong.

\section{c. Pandangan (Critize)}

Dari analisi dan talaah beberapa jurnal Menunjukkan bahwa hambatan pelaksanaan SOP (Standar Operasinal Prosedur) serta komunikasi antar petugas koder dengan petugas medis perawat dan dokter sehingga menimbulkan masalah seperti dokumen tidak lengkap, diagnosa pasien belum di koding, dan terjadinya kesalahan dalam pengkodean sehingga berdapak pada kelengkapan dan keakuratan berkas rekam medis.

\section{d. Pandangan (Synthesize)}

Perbandingan hasil antar jurnal penelitian memenukan Masih adanya tulisan dokter yang tidak jelas sehingga menyulikan petugas koder dalam penggodean. Masih ditemukan lembaran rekam medis tidak ditulis diagnosa sehingga pemberian kode diagnosa petugas hanya melihat pada rekapan kode penyakit tetapi tidak mencek kembali kebenaran pada ICD10. Maka dari tersebut petugas rekam medis diharapakan lebih teliti dan mencek kembali kebenaranya di ICD10 , serta perlunya pelatihan koding petugas sehingga menghasilkan pelaporan yang baik untuk mutu rumah sakit menjadi lebih baik untuk kedepannya.

Hal tersebut sejalan dengan (Depkes Ri, 2006) kecepatan dan ketepatan diagnosa pemberian kode dari sautu diagnosa sangat tergantung kepada pelaksanaan yang mengenai rekam medis tersebut yaitu, diagnosa yang kurang spesifik, ketrampilan petugas koding dalam memilih kode, tulisan dokter yang sulit dibaca dan tengga kesehatan lainnya.

\section{e. Ringkasan (Summarize)}

Dari beberapa jurnal bisa di analisis bahwa sanya faktor ketidak akuratan penulisan diagnosa dikarenakan tulisan dokter, jelas dan tidak dapat dibaca serta dokter menggunkan singkatan tidak sesaui dengan SOP yang ada, ketidak lengkapan penulisan diagnosa karena kurangnya kerja sama antar petugas medis yang seharusnya adanya 
kumunikasi jika terdapat kesalahan dan terdapanya resume medis kosong, masih ditemukan perbedaan diagnose diresume keluar dan fomulir laporan kematian sehingga menyebabkan pengisisan tidak lengkap berdapak terhadap keakuratan dan kelengkapan.

$$
\text { Sedangkan dari beberapa }
$$
penelitian bahwa ketidak tepatan dan ketidak akuratan diagnosa pasien rawat inap hal ini dikarenakan kurangnya ketelitian petugas dalam pemberian pengodean maupun penulisan diagnose dan juga petugas masih menggunakan pedoman penggodean yang dibuat seniri di Microsoft excel. Masih adanya tulisan dokter yang tidak jelas sehingga menyulikan petugas koder dalam penggodean. Masih ditemukan motivasi, dokter tidak mendiagnosa secara spesifik sehingga infomasi salah sebaiknya koder harus adanya pelatihan dan meningkatkan kompetensi.

\section{Kesimpulan}

1. Ketepatan pengkodean diagnosa penyakit pasien rawat inap leteratur riview dilihat dari diagnosa dokter yang spesifik dan penulisan diagnosa dengan ICD-10 yang lengkap dan akurat. Faktor lain yang menyebakan ketidak tepatan karena petugas kurang keteliti. Dikarenakan betapa pentingnya melaksanakan kodefikasi dengan tepat sebagai laporan mortalitas dan morbiditas.

2. Kejelasan penulisan diagnosa penyakit beredasarkan literatur riview hal ini disebakan kurangnya lembaran rekam medis tidak ditulis diagnosa sehingga pemberian kode diagnosa petugas hanya melihat pada rekapan kode penyakit tetapi tidak mencek kembali kebenaran pada ICD10. Maka dari tersebut petugas rekam medis diharapakan lebih teliti dan cek kembali kebenaranya di ICD-10, serta perlunya pelatihan koding petugas sehingga menghasilkan pelaporan yang baik untuk mutu rumah sakit menjadi lebih baik untuk kedepannya.

Sedangkan menurut Adhani Windari, Anton Kristijono (2016),Yeni Tri Utami, Nita Rosmalia (2017), dan Heri Hernawan, Kori Puspita Ningsih,Winarsih (2017) salah satu penyebanya yaitu koder kurang berpengalam dan belum pernah mengikuti pelatihan dan kurangnya tangggung jawab dokter dalam menuliskan diagnosa utama pasien dengan jelas akibat terburu-buru akhirnya tidak terselesaikan, sehingga menyulitkan koder untuk membaca diagnosa yang ditulis dokter . Hal ini berdampak terhadap kulitas ketepatan berpengaruh terhadap informasi yang dihasilkan.

3. Kelengkapan penulisan diagnosa penyakit berdasarkan literatur riview pengangaruhui oleh 3 faktor yaitu: faktor tenaga medis dokter dan perawat, faktor tenaga rekam medis.Tulisan dokter sulit untuk dibaca dan menuliskan diagnosis dengan singkatan. Sedangkan dari faktor tenaga rekam medis koder kesulitan dalam membaca tulisan dokter. 


\section{Ucapan Terima Kasih}

Pada kesempatan ini peneliti mengucapkan terimakasih kepada Pimpinan STIKS Dharma Landbouw dan Ibu Ketua Program Studi D3 Rekam Medis dan Informasi Kesehatan yang telah banyak memberikan saran dan masukanya sehingga persiapan jurnal ini diselesaikan sesuai dengan harapan.

\section{Daftar Pustaka}

Affrilia, Inneke. 2017 Ketepatan Kode Diagnosis Pada Klinik Bedah BerdasarkanIcd-10 Di Rsud Watestriwulan I, Yogyakarta: Sekolah Tinggi Ilmu Kesehatan Jendral Ahmad Yani.

Anugra Hervey Pepo, Aurelius. Noor Yulia. 2015. Kelengkapan Penulisan Diagnosa Pada Resume Medis Terhadap Ketepatan Pengkodean Klinis Kasusu Kebidanan, Semarang: Jurnal Manajemen Informasi Kesehatan Indonesia http://ejournal.poltekkessmg.ac.id/ojs/index.php/jrk

Bandini, Nurul. 2018 Tentang Hubungan Ketepatan Penulisan Diagnosis DenganKeakuratan Kode Diagnosis Pasien Rawat InapDi Rumah Sakit Bhayangkara Polda Diy, Yogyakarta: Universitas Jendral Ahcmad Yani

Depkes RI. 2006. Pedoman Penyelenggaraan dan Prosedur Rekam Medis Rumah Sakit di Indonesia Revisi II, Jakarta: Direktorat Jendral Bina Pelayanan Medik.

Departemen Kesehatan RI. 2006, Pedoman Penyelenggaran Dan Prosedur Rekam Medis Rumah Sakit Di Indonesia Revisi II, Jakarta: DEPKES RI
Hatta, Gemala R. 2011. Pedoman Manajemen Informasi Kesehatan di Sarana Pelayanan Kesehatan, Jakarta: Universitas Indonesia.

Hernawan, Heri. Kori Puspita Ningsih. Winarsih. 2017. Ketepatan Kode Diagnosa sisitem sirkulasi di Klinik Jantung RSUD Water, Yogyakarta: Jurnal Kesehatan Vokasional.

Ismainar, Hetty. 2015Manajemen Unit Kerja: Untuk Perekam Medis dan Informasi Kesehatan masyarakat keperawatan dan Kebidanan, Deepublish, Yogyakarta:

Notoatmodjo, Soekidjo. 2001. Metodologi Penelitian Kesehatan, Jakarta: Rineka Cipta.

Peraturan Mentri Kesehatan Republik Indonesia Nomor 147/Menkes/per/III/2010 Tentang perizinan Rumah Sakit

Peraturan Mentri Kesehatan Republik Indonesia Nomor 269/Menkes/per/III/2010

Peraturan Presiden Republik Indonesia Nomor 12 Tahun 2013 Tentang Jaminan Kesehatan

Pratiwi, Nurul 2016.Tinjauan Kesesuaian Dan Ketepatan Kode DiagnosaPasien Rawat Inap Pada Simrs Dengan Berkas Rekam Medis Di Rsud Panembahan Senopati Bantul, Yogyakarta: Sekolah Tinggi Ilmu Kesehatan Jendral Ahmad Yanihttp://ojs.stikeslandbouw.ac .id/index.php/ahi

Rahmatul Ilmi, Laili. 2018, Quality Assurance Pelayanan Kesehatan Di Rumah Sakit. Jawa tengah: Konsorium RS Islam

Sabarguna, Boys. 2005, Keakuratan Kode Dignosa dengan ICD-10 Di Puskesmas Pengasih I Dan Pengasih II. Yogyakarta: Jurnal Manajemen Informasi Kesehatan 
STIKes, Dharma Landbouw. 2020.

Pedoman Penulisan Karya Tulis

Ilmiah, Padang: STIKes Dharma

Landbouw. 